\title{
"Small airways disease" in children: no test is best
}

\author{
L I LANDAU, C M MELLIS, P D PHELAN, B BRISTOWE, AND L McLENNAN
}

From the Department of Thoracic Medicine, Royal Children's Hospital, Melbourne, Australia

ABSTRACT Tests claimed to detect small airway disease were evaluated in children. Fifty-two subjects who were normal, 30 with cystic fibrosis (CF), and 35 with asthma were selected on the basis of normal spirometry, informed consent being obtained from them and their parents. Tests undertaken were measurement of maximum expiratory flow volume curves breathing air and a helium-oxygen gas mixture, single breath nitrogen washout curves, lung volumes, and, except in the normal subjects, measurement of arterial oxygen tension. Closing volumes were normal in most children with CF and asthma, whereas the slope of the alveolar plateau was abnormal in $83 \%$. Maximum expiratory flow rate at $50 \%$ of total lung capacity was reduced in $65 \%$ and maximum mid-expiratory flow rate in $57 \%$; residual volume increased in $51 \%$, and results of other tests were abnormal in less than $50 \%$ of children.

There was evidence suggesting that lung disease was more patchy in children with mild CF than in those with interval phase asthma. These tests do not detect specific pathological processes in small airways but reflect the consequences of small airway abnormalities, which may vary in the same disease as well as in different diseases. No one test alone appears most useful. Together they contribute to understanding the functional abnormalities present in each individual.

There is evidence that most obstructive airway diseases begin in the periphery of the lung and interfere with the function of small airways long before they produce significant symptoms or alter commonly used pulmonary function tests (Anthonisen et al, 1968). Abnormalities in small airways may be the earliest changes in the pathogenesis of chronic bronchitis (Anthonisen et al, 1968; Matsuba and Thurlbeck, 1973) and cystic fibrosis (Mellins, 1969; Landau and Phelan, 1973). Moreover, epidemiological studies indicate that airway changes associated with childhood illnesses may predispose to chronic lung disease in adult life (Colley et al, 1973; Burrows et al, 1977). Disease of the peripheral airways has also been detected in subpopulations of children with asthma during the interval phase (Hill et al, 1972).

In many of these conditions the changes are irreversible when the patient seeks medical attention for symptoms. If the diagnosis could be established at an earlier stage treatment might be more effective. Bode et al (1975) reported small airway obstruction in chronic bronchitis to be partially reversible with bronchodilator therapy and cessation of smoking if this was done early in the course of the disease.
Several techniques have been described that are claimed to be valuable in detecting early small airway disease. Obstruction to small airways can lead to alterations in dynamic compliance (Woolcock et al, 1969; Hill et al, 1972) but this test is unsuitable for routine use. The alveolar-arterial oxygen gradient has been advocated in the early detection of pulmonary function abnormalities in cystic fibrosis (Lamarre et al, 1972). Changes in the slope of the alveolar plateau and the closing volume from a single breath nitrogen washout have been described as sensitive measurements of small airway disease (McCarthy et al, 1972; Mansell et al, 1972; Buist and Ross, 1973). Similarly, measuring the effect of breathing gases of different density, such as a helium-oxygen mixture, on maximum expiratory flow has been described as useful (Despas et al, 1972; Fox et al, 1974; Gelb et al, 1975). There is no general agreement on the relative yield or sensitivity and no information on the relationship of these tests to each other, particularly in children with mild lung disease.

In an attempt to evaluate these tests normal children and children with asthma and cystic fibrosis who had normal vital capacity (VC) and forced expiratory volume in one second $\left(\mathrm{FEV}_{1}\right)$ 217 
were studied. They were considered to be those without evidence of severe lung disease.

\section{Material and methods}

Altogether 117 children aged 8-18 years were studied. Thirty children with cystic fibrosis proved by estimation of sweat sodium and chloride and 35 with asthma in an interval phase were selected on the basis of their ability to perform the required manoeuvres and the presence of normal

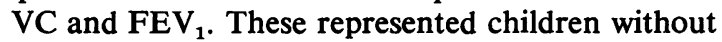
extensive obstructive airway disease. Those asymptomatic except for short periods of mild wheeze (asthma) or cough (cystic fibrosis) were classified as having minimal disease, those with persistent symptoms as moderate, and an intermediate group of children with more prolonged symptomatic periods were termed mild. This classification was done independently by one of the authors not involved in the performance or analysis of pulmonary function tests. Fifty-two healthy children of similar age without a history of recurrent or persistent respiratory symptoms were included to determine normal values. These children were attending as part of a continuing study of normal pulmonary function in Melbourne schoolchildren. Informed consent to the studies was obtained from both children and parents and separate permission was obtained in the case of the children with asthma and CF for the arterial puncture.

$\mathrm{VC}$ and $\mathrm{FEV}_{1}$ and maximum mid-expiratory flow rate between $25 \%$ and $75 \%$ of VC (MMEFR) were recorded with a nine litre water filled spirometer.

Maximum expiratory flow volume (MEFV) curves were recorded with the patient sitting in a constant pressure flow displacement plethysmograph (Leith, D E, and Mead, J; N H, and L I, Procedures for Standardised Measurements of Lung Mechanics) and performing a forced vital capacity manoeuvre. Volume change measured in the plethysmograph was recorded on the abscissa and flow, measured at the mouth with a Fleisch No 4 pneumotachograph and Sanborn P270 pressure transducer was recorded on the ordinate. The curve was displayed on a Tektronix 564B storage oscilloscope and photographed. The curve was quantified by measuring maximum flow (Vmax) at $50 \%$ total lung capacity. Absolute $V \max$ was divided by total lung capacity and expressed as a fraction of total lung capacity per second, thus allowing lungs of different sizes to be compared (Zapletal et al, 1969).

The subject then breathed a mixture of $80 \%$ helium and $20 \%$ oxygen for five minutes and re- peated the MEFV manoeuvre while still breathing the mixture. The signal from the pneumotachograph was corrected electrically for the different viscosity of the helium-oxygen gas mixture. From the air MEFV curve, flow rates were calculated at $50 \% \mathrm{VC}$ and compared to the flow rate at $50 \%$ VC breathing the helium-oxygen gas mixture. The change in flow at $50 \%$ VC was calculated as a fraction of the Vmax breathing room air and expressed as a percentage increase in flow. The helium and air MEFV curves were superimposed to determine the point at which the curves crossed and this intersecting point (VisoV) was expressed as percent of vital capacity (Gelb et al, 1975).

Thoracic gas volume was measured in the plethysmograph (DuBois et al, 1956) and total lung capacity (TLC) and residual volume (RV) were obtained.

Closing volume, closing capacity, and the slope of the alveolar plateau were measured using the modification of the Fowler single breath technique described by Anthonisen et al (1969). The subject took a single vital capacity breath of oxygen from $\mathrm{RV}$, and during the subsequent slow vital capacity expiration nitrogen concentration at the mouth was monitored with a rapid response nitrogen meter (Hewlett Packard 47302A). Expired volume was simultaneously measured with a spirometer. The two signals were displayed on an XY recorder. The flow signal was also displayed on an oscilloscope to ensure that the subject maintained flow rates between 0.2 and 0.3 LPS. The closing volume and closing capacity were calculated at the point of inflection due to an increase in nitrogen concentration at the end of the alveolar plateau. The slope of the alveolar plateau (phase III) was obtained by drawing the line of best fit through phase III, excluding the first $30 \%$ of the vital capacity. The slope was expressed as the increase in nitrogen concentration per litre expired. A minimum of three reproducible tracings was obtained from each subject (Buist and Ross, 1973).

Arterial blood was sampled from the radial artery in 17 of the children with asthma and all those with cystic fibrosis. This blood was analysed for partial pressure of oxygen and carbon dioxide and arterial $\mathrm{pH}$ within minutes of collection. The alveolar oxygen tension was calculated using the alveolar gas equation (West, 1965).

\section{Results}

The results (mean and standard deviation) for each test in the normal children, those with cystic fibrosis, and those with asthma are shown in table 1. The range for the slope of the alveolar 
Table 1 Anthropomorphic data and results (mean士standard deviation) for tests performed in each group of children

\begin{tabular}{|c|c|c|c|c|c|c|c|c|c|c|}
\hline & $\begin{array}{l}\text { Age range } \\
\text { (Years) }\end{array}$ & $\operatorname{Sex}$ & $\begin{array}{l}\text { Height } \\
(\mathrm{cm})\end{array}$ & $\begin{array}{l}\text { MMEF } \\
\text { (\% Predicted })\end{array}$ & $\begin{array}{l}\dot{V} \max \\
(T L C / s)\end{array}$ & $\begin{array}{l}R V / T L C \\
(\%)\end{array}$ & $\begin{array}{l}\mathrm{He} \\
(\%)\end{array}$ & $\begin{array}{l}\text { Slope } \\
\left(\% N_{2} / L\right)\end{array}$ & $\begin{array}{l}C V \\
(\%)\end{array}$ & $\begin{array}{l}(A-a) d O_{2} \\
(m m H g)\end{array}$ \\
\hline Normal & $8 \cdot 5-18 \cdot 0$ & $\begin{array}{l}30 M \\
22 F\end{array}$ & $154 \pm 14$ & $99 \cdot 7 \pm 23 \cdot 8$ & $0.72 \pm 0.21$ & $19 \cdot 8 \pm 7 \cdot 9$ & $38 \pm 16$ & $1 \cdot 13 \pm 0 \cdot 46$ & $11 \pm 5$ & - \\
\hline Cystic fibrosis & $8 \cdot 9-24 \cdot 8$ & $\begin{array}{l}21 \mathrm{M} \\
9 \mathrm{~F}\end{array}$ & $150 \pm 15$ & $61 \cdot 6 \pm 28 \cdot 9$ & $0.31 \pm 0.26$ & $32 \cdot 9 \pm 10 \cdot 1$ & $25 \pm 19$ & $5 \cdot 89 \pm 4 \cdot 13$ & $14 \pm 9$ & $30 \pm 9$ \\
\hline Asthma & $10 \cdot 6-16 \cdot 8$ & $\begin{array}{l}31 \mathrm{M} \\
\mathbf{4 F}\end{array}$ & $150 \pm 12$ & $52 \cdot 2 \pm 30 \cdot 6$ & $0 \cdot 28 \pm 0 \cdot 22$ & $32 \cdot 4 \pm 9 \cdot 3$ & $37 \pm 21$ & $4 \cdot 17 \pm 3 \cdot 05$ & $22 \pm 13$ & $17 \pm 12$ \\
\hline
\end{tabular}

MMEF (maximum mid-expiratory flow rate); $\dot{\text { max }}$ (maximum expiratory flow at $50 \%$ total lung capacity); RV/TLC (residual volume/total lung capacity); He (\% increase in V̈max breathing a helium-oxygen gas mixture); Slope (slope of phase III of single breath nitrogen washout curve); $\mathrm{CV}$ (closing volume); (A-a) $\mathrm{dO}_{2}$ (alveolar-arterial oxygen difference).

plateau in normal children was 0.5 to $2 \cdot 0 \%$ nitrogen/litre and was independent of height and age. These values in children were similar to those in young adults (Buist and Ross, 1973). The upper limit of normal for closing volume in the normal children was $20 \%$.

All normal children of this age had an increase in flow breathing a helium-oxygen gas mixture. There was some increase in response to helium and a corresponding decrease in the $V$ iso $V$ with increasing age and increasing height; however, the change was small and the correlation not statistically significant. The percentage increase in flow at $50 \%$ VC breathing the helium-oxygen mixture varied from $12 \%$ to $90 \%$. The point of VisoV in the normal children varied from $0-35 \%$ vital capacity. There was no apparent difference in sensitivity between measurement of helium response at $50 \% \mathrm{VC}$ and the $\mathrm{Viso} \mathrm{V}$ in the children with asthma and cystic fibrosis. Consequently, helium responsiveness at $50 \%$ VC was used to describe the changes observed and $12 \%$ was taken as the lower limit of normal.

A scattergram shows the range of normal values for each test with the individual results obtained in the children with CF and asthma (fig 1).

Table 2 lists the percentage of children with abnormal results to the various tests used. Measurement of the slope of the alveolar plateau on the single breath nitrogen washout curve had the highest percentage of abnormalities. Of the children with asthma or CF $83 \%$ had an increased slope compared with $65 \%$ who had a reduction in Vmax from the MEFV curve. Results of all other

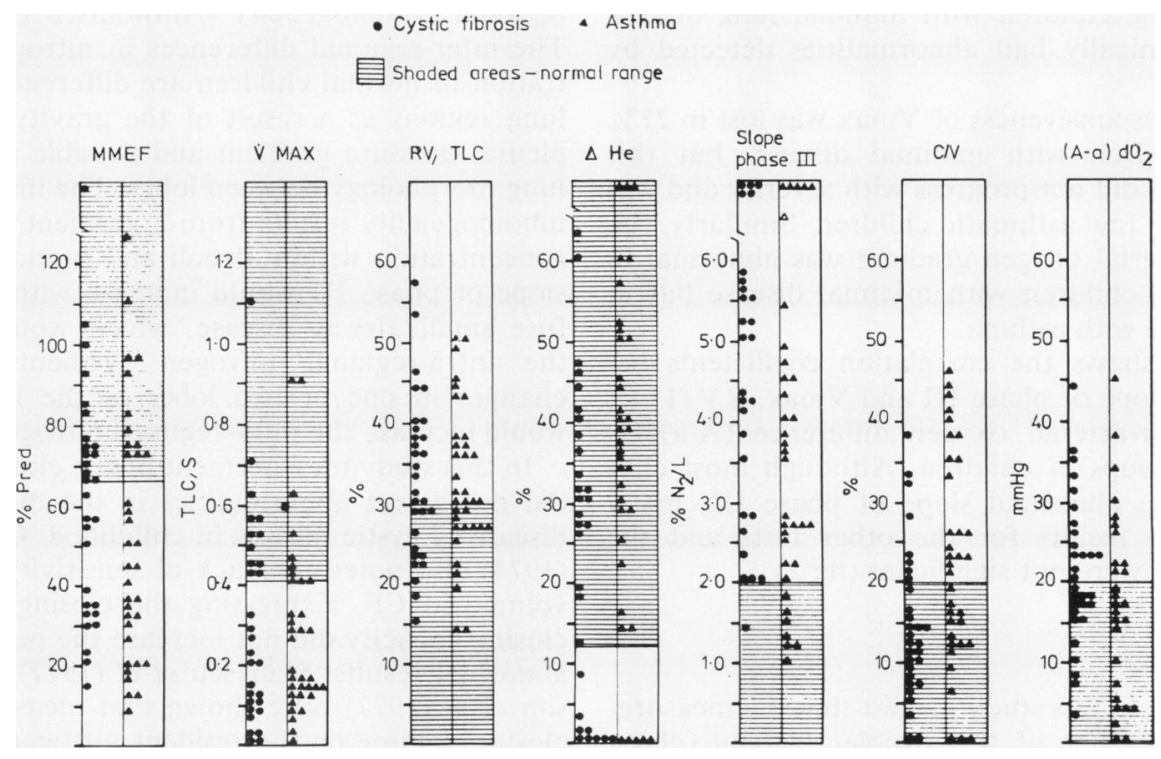

Fig 1 Scattergram showing normal range (shaded area) for each test with individual results for children with $C F(O)$ and asthma $(\Delta)$ plotted. 
Table 2 Percent of each group with abnormal results

\begin{tabular}{|c|c|c|c|c|c|c|c|c|}
\hline \multicolumn{5}{|l|}{ Cystic fibrosis } & \multicolumn{3}{|c|}{ Asthma } & \multirow{2}{*}{$\begin{array}{l}\text { Combined } \\
\text { Total }\end{array}$} \\
\hline Test & Minimal & Mild & Moderate & Total & Mild & Moderate & Total & \\
\hline $\begin{array}{l}\text { MMEF } \\
\text { Vmax } \\
\text { RV/TLC } \\
\text { He } \\
\text { Slope } \\
\text { CV } \\
\text { (A-a)dO, }\end{array}$ & $\begin{array}{r}9 \% \\
9 \% \\
18 \% \\
27 \% \\
64 \% \\
9 \% \\
55 \%\end{array}$ & $\begin{array}{r}50 \% \\
75 \% \\
50 \% \\
25 \% \\
100 \% \\
13 \% \\
63 \%\end{array}$ & $\begin{array}{r}91 \% \\
100 \% \\
91 \% \\
45 \% \\
100 \% \\
55 \% \\
36 \%\end{array}$ & $\begin{array}{l}50 \% \\
60 \% \\
53 \% \\
33 \% \\
87 \% \\
27 \% \\
50 \%\end{array}$ & $\begin{array}{l}15 \% \\
23 \% \\
15 \% \\
0 \% \\
46 \% \\
38 \% \\
25 \%\end{array}$ & $\begin{array}{l}91 \% \\
96 \% \\
68 \% \\
18 \% \\
96 \% \\
64 \% \\
45 \%\end{array}$ & $\begin{array}{l}63 \% \\
69 \% \\
49 \% \\
11 \% \\
77 \% \\
54 \% \\
39 \%\end{array}$ & $\begin{array}{l}57 \% \\
65 \% \\
51 \% \\
22 \% \\
83 \% \\
42 \% \\
45 \%\end{array}$ \\
\hline No in group & 11 & 8 & 11 & 30 & 13 & 22 & 35 & 65 \\
\hline
\end{tabular}

tests were abnormal in less than $60 \%$ of the children.

The slope of phase III was abnormal in most children with mild symptom scores. Two-thirds of the children with cystic fibrosis who had clinically graded minimal disease had an abnormal slope of phase III. All children with mild to moderate cystic fibrosis, $46 \%$ with mild asthma, and $96 \%$ with moderate disease had an increased slope of the alveolar plateau.

Measurement of the closing volume was not a sensitive index of abnormal lung function in children with cystic fibrosis as only $27 \%$ had a raised measurement. However, $54 \%$ of all of those with asthma had values above the normal range. The closing volume was abnormal in $38 \%$ of those with mild asthma.

The number of children in each clinical group with an abnormal result for MMEF, Vmax, or $\mathrm{RV} / \mathrm{TLC}$ ratio increased with increasing severity. Few of those children with minimal lung disease assessed clinically had abnormalities detected by these tests.

Helium responsiveness of Vmax was lost in $27 \%$ of CF children with minimal disease, but this abnormality did not progress with severity and was seen in very few asthmatic children. Similarly, the alveolar-arterial oxygen gradient was abnormal in $55 \%$ of CF children with minimal disease but in few of those with asthma.

Table 3 shows the correlation coefficients between the slope of phase III and Vmax, RV/TLC, and alveolar-arterial oxygen difference $(\mathrm{A}-\mathrm{a}) \mathrm{dO}_{2}$ for both groups of children. Although most children had an abnormal slope of phase III, many had normal results for the other tests and the correlations were not significant (fig 2).

\section{Discussion}

The findings in this study suggest that the measurement of the slope of the alveolar plateau (phase III) of the single breath nitrogen washout curve is the test most likely to detect abnormal pul-

Table 3 Correlation of slope phase III of single breath nitrogen washout with other tests

\begin{tabular}{|c|c|c|c|}
\hline \multicolumn{4}{|c|}{ Cystic fibrosis } \\
\hline $\begin{array}{l}\dot{V} \max \\
\mathrm{RV} / \mathrm{TLC} \\
\mathrm{A-adO} \mathbf{O}_{2}\end{array}$ & - & $\begin{array}{l}\text { Slope phase III } \\
\text { Slope phase III } \\
\text { Slope phase III }\end{array}$ & $\begin{array}{l}r=-0.34 \text { (NS) } \\
r=0.57(\mathrm{NS}) \\
r=0.32(\mathrm{NS})\end{array}$ \\
\hline $\begin{array}{l}\text { Asthma } \\
\text { V́max } \\
\text { RV/TLC } \\
\text { A-adO, }\end{array}$ & $\frac{-}{-}$ & $\begin{array}{l}\text { Slope phase III } \\
\text { Slope phase III } \\
\text { Slope phase III }\end{array}$ & $\begin{array}{l}r=-0.34 \text { (NS) } \\
r=0.20 \text { (NS) } \\
r=0.62 \text { (NS) }\end{array}$ \\
\hline
\end{tabular}

monary function in children with presumed obstructive lung disease. Buist and Ross (1973) found $\frac{\curvearrowright}{\not}$ this measurement also the most sensitive test for $\cong$ asymptomatic smokers.

The increase in nitrogen concentration during phase III is a result of maldistribution of ventilation and the small slope seen in normal children due to a combination of inter-regional and intraregional inhomogeneity (Anthonisen et al, 1968). The inter-regional differences in nitrogen concen- $x$ tration in normal children are differences between $\frac{5}{3}$ lung regions as a result of the gravity dependent pleural pressure gradient and possible variation in lung morphology between lobes. The intra-regional inhomogeneity results from a gradient of nitrogen $\frac{9}{2}$ concentration within alveoli and bronchioles. The $\rightarrow$ slope of phase III would increase with either diffuse small airway disease, which would increase $N_{0}$ the intra-regional nitrogen gradient, or focal ${ }^{\circ}$ changes in one or two lobes of the lung, which ${ }_{N}$ would increase the inter-regional nitrogen gradient. W

In this study measurement of the closing volume did not detect abnormalities in the minimal lunge disease of cystic fibrosis in childhood. Cooper et al (1974) also noted this lack of sensitivity of closing ? volume in CF. Expressing the closing volume as closing capacity did not increase the percentage of $\underset{\mathbb{D}}{\stackrel{O}{D}}$

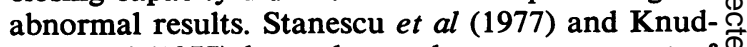
son et al (1977) have shown that measurement of $\stackrel{\mathbb{Q}}{\Omega}$ closing volume by the resident nitrogen technique is less sensitive than the bolus method. It is $\delta$ unlikely, however, that the bolus method in 


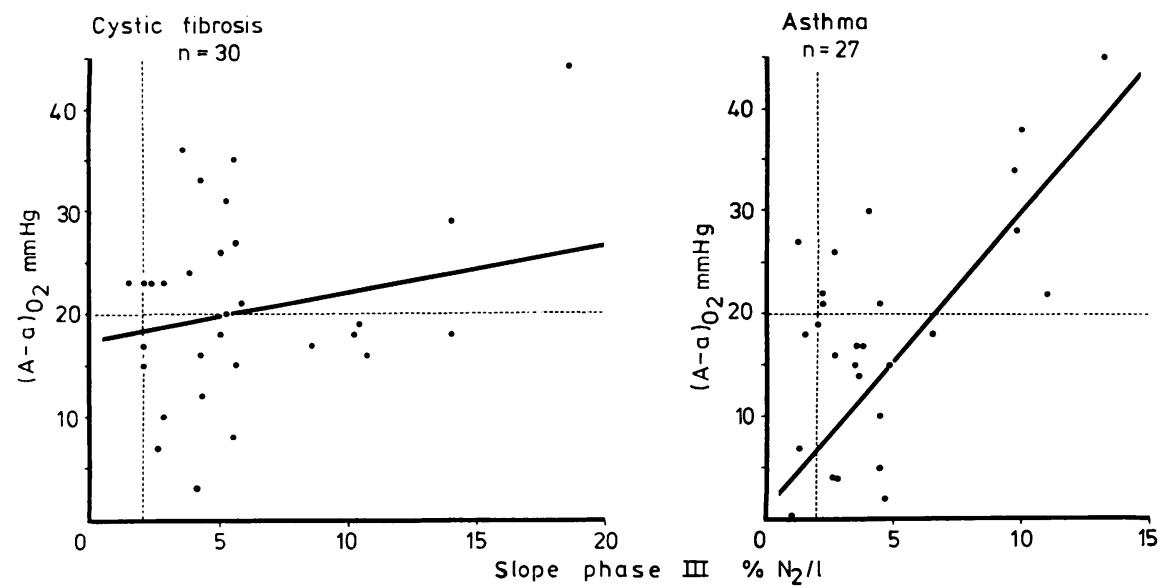

Fig 2 Relationship between alveolar-arterial oxygen gradient (ordinate) and slope of phase III of nitrogen washout curve (abscissa) for children with cystic fibrosis and asthma. Upper limits of normal shown as interrupted lines; regression line is shown.

these children would significantly alter these observations.

Only $23 \%$ of children with cystic fibrosis had a raised closing volume, whereas $54 \%$ of those with asthma had values above the normal range. Development of a closing volume requires either closure or cessation of contribution from basal airways during expiration. This uniform closure of basal airways, which is dependent on diffuse airway narrowing at the lung bases, may not be a consequence of the early disease in small airways in children with cystic fibrosis. The slope of phase III on the other hand is affected by any abnormality of intrapulmonary gas distribution as well as regional differences. In asthma most of those with an abnormal slope have a raised closing volume suggesting uniform and diffuse airway disease. In cystic fibrosis one could speculate that the abnormality is patchy or more localised to the upper lobes resulting in an abnormal slope of phase III with a normal closing volume.

Mellis and Landau (1976) noted that a large proportion of children with cystic fibrosis had a raised slope of phase III that did not fall after a breath-hold. This would suggest a significant contribution by focal regional disease and not solely diffuse small airway changes. This is supported by the finding of focal radiological changes in children with cystic fibrosis and minimal lung disease (Alderson et al, 1974). Mellins (1969) postulated that airway obstruction in cystic fibrosis may be less uniform than in asthma and contribute to the pronounced concavity on the flow volume curves observed in some children with this condition.

Helium-oxygen flow volume curves failed to detect abnormalities in small airways in most children with interval phase asthma and many with lung changes due to cystic fibrosis. Abnormalities in the distribution of ventilation, however, could be detected by an abnormal slope and raised closing volume on the single breath nitrogen washout curve so that disease in small airways was probably present. Disease in larger airways could mask these changes by maintaining helium responsiveness in most asthmatics and CF children with moderate lung disease. The group in which this test detected some abnormality was the minimal disease CF group. Follow-up to define progress and reversibility will be useful to determine the significance of this observation.

Lamarre et al (1972) and DeMuth et al (1962) found evidence of abnormal ventilation distribution in early lung disease in CF that was reflected by changes in oxygen equilibration index, nitrogen washout, and the $\mathrm{A}-\mathrm{adO}_{2}$. In our study the alveolar-arterial oxygen gradient was often normal in the presence of an abnormal slope of the alveolar plateau. The $\mathrm{A}-\mathrm{adO}_{2}$ was probably underestimated with the technique used in this study as the alveolar oxygen was determined from the alveolar gas equation. This is the most practical method of performing this test, however, and would be that usually used. As in this study, Lamarre et al (1972) found a difference between 
a population of children with cystic fibrosis and a population of normal children in the $\mathrm{A}-\mathrm{adO}_{2}$ measurement, but most children with cystic fibrosis still had values within two standard deviations of the normal mean.

There was poor correlation between the various tests measured and although progression in one leads to more pronounced abnormality in another, the degree of change varied greatly. Lamarre et al (1972) also found poor correlation between the $\mathrm{A}-\mathrm{adO}_{2}$ and the clinical or radiological scores, and Fox et al (1974) found poor correlation between the helium responsiveness and radiographic score. Apparently there are variations in early lung disease in these conditions that lead to different functional abnormalities with various tests. Followup of these patients may help to indicate the significance of these functional differences.

The ultimate place of these tests in the assessment of children with obstructive lung disease is not clear. Measurement of the slope of the alveolar plateau does appear to be a relatively simple and sensitive test for detecting early airway disease. It is so often abnormal, however, that its potential therapeutic significance remains in question. It appears to be a non-specific test unrelated to the presence of abnormalities in other tests of so-called small airway disease and does not necessarily lead to impaired arterial oxygenation.

Abnormal helium responsiveness detects some children with mild pulmonary disease in cystic fibrosis, but these children also have abnormal slopes on a single breath nitrogen washout. Helium responsiveness is not abnormal in mild interval phase asthma. The RV/TLC was abnormal in $51 \%$ of children, MMEF in $57 \%$, and $V \max$ at $50 \%$ TLC on an MEFV curve was reduced in $65 \%$ of children with mild airway disease. These tests remain useful, practical means of regular assessment.

Each test appears to reflect different alterations in pulmonary function. Together they contribute to understanding the physiological abnormalities present in each individual. Until long term studies are performed, however, the practical therapeutic and prognostic significance of these findings cannot be clearly defined.

\section{References}

Anthonisen, N R, Bass H, Oriol, A, Place, R E G, and Bates, D V (1968). Regional lung function in patients with chronic bronchitis. Clinical Science, 35, 495-511.

Anthonisen, N R, Danson, J, Robertson, P C, and Ross, W R D (1969). Airway closure as a function of age. Respiratory Physiology, 8, 58-65.

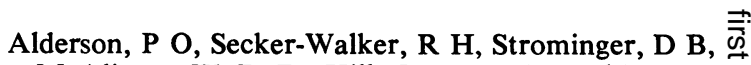
McAlister, W R D, Hill, R L, and Markham, Jo (1974). Quantitative assessment of regional ventila- 흠 tion and perfusion in children with cystic fibrosis. Radiology, 3, 151-155.

Bode, F R, Dosman, J, Martin, R R, and Macklem, 을 P T (1975). Reversibility of pulmonary function os abnormalities in smokers. American Journal of $\vec{\circ}$ Medicine, 59, 43-52.

Buist, A S, and Ross, B B (1973). Quantitative analysis $\overrightarrow{\vec{\omega}}$ of the alveolar plateau in the diagnosis of early $\stackrel{S}{P}$ airway obstruction. American Review of Respir- $\vec{x}$ atory Disease, 108, 1078-1087.

Burrows, B, Knudson, R J, and Lebowitz, M D (1977). The relationship of childhood respiratory illness to adult obstructive airway disease. American Review $\vec{V}$ of Respiratory Disease, 115, 751-760.

Colley, J R T, Douglas, J W B, and Reid, D D (1973). 을 Respiratory disease in young adults: Influence of $\vec{D}$ early childhood lower respiratory tract illness, socialo class, air pollution, and smoking. British Medical Journal, 3, 195-198.

Cooper, D M, Doron, I, Mansell, A L, Bryan, A C, 厄ै and Levison, $H$ (1974). The relative sensitivity of closing volume in children with asthma and cystic 0 fibrosis. American Review of Respiratory Disease, 109, 519-524.

DeMuth, G R, Howatt, W F, and Talmer, N $S \stackrel{\%}{\%}$ (1962). Intrapulmonary gas distribution in cystic $\stackrel{\mathbb{Q}}{\varrho}$ fibrosis. American Journal of Diseases of Children, $\stackrel{\overrightarrow{\vec{A}}}{\overrightarrow{2}}$ 103, 129-135.

Despas, P J, Leroux, M, and Macklem, P T (1972). Site of airway obstruction in asthma as determined by measuring maximum expiratory flow breathing air and a helium-oxygen mixture. Journal of Clinical Investigation, 51, 3235-3243.

DuBois, A B, Botelho, S Y, Bedell, G N, Marshall, R, and Comroe, J H jun (1956). A rapid plethysmo- $\frac{}{3}$ graphic method measuring thoracic gas volumes; $a-$ comparison with nitrogen washout method for measuring functional residual capacity in normal $₹$ subjects. Journal of Clinical Investigation, 35, 322-응

326.
Fox, W W, Bureau, M A, Taussig, L A, Martin, R R, 을 and Beaudry, P H (1974). Helium flow-volume curves in the detection of early small airway disease. Pediatrics, 54, 293-299.

Gelb, A F, Molony, P A, Klein, E, and Aronstam, N P S (1975). Sensitivity of volume of isoflow in the detection of mild airway obstruction. American $R e$ ? view of Respiratory Disease, 112, 401-405.

Hill, D J, Landau, L I, and Phelan, P D (1972). Small airway disease in asymptomatic adolescents. Ameri- -9 can Review of Respiratory Disease, 106, 873-880. To

Knudson, $\mathbf{R}$ J, Lebowitz, $\mathbf{M}$ D, Burton, A P, andọ Knudson, D E (1977). The closing volume test: Evaluation of nitrogen and bolus methods in a ran- $\frac{}{\Phi}$ dom population. American Review of Respiratory Disease, 115, 423-431.

Lamarre, A, Reilly, B J, Bryan, A C, and Levison, H (1972). Early detection of pulmonary functiono 
abnormalities in cystic fibrosis. Pediatrics, 50, 291298.

Landau, L I, and Phelan, P D (1973). The spectrum of cystic fibrosis: A study of pulmonary mechanics in 46 patients. American Review of Respiratory Disease, 108, 593-602.

McCarthy, D S, Spencer, R, Greene, R, and MilicEmili, J (1972). Measurement of "closing volume" as a simple and sensitive test for early detection of small airway disease. American Journal of Medicine, 52, 747-753.

Mansell, A, Bryan, C, and Levison, H (1972). Airway closure in children. Journal of Applied Physiology, 33, 711-714.

Matsuba, K, and Thurlbeck, W M (1973). Disease of the small airways in chronic bronchitis. American Review of Respiratory Disease, 107, 552-558.

Mellins, R B (1969). The site of airway obstruction in cystic fibrosis. Pediatrics, 44, 315-318.

Mellis, C M, and Landau, L I (1976). Ventilatory disturbances in children with obstructive lung disẹase. Australian Paediatric Journal, 12, 77-82.
Stanescu, D, Veriter, C, and Brasseur, L (1977). Difference between the $\mathrm{He}$ bolus and $\mathrm{N}_{2}$ technique for measuring closing volume. Journal of Applied Physiology, 42, 859-864.

West, J B (1965). Ventilation/blood flow and gas exchange, pp 107-108. Blackwell, Oxford.

Woolcock, A J, Vincent, N J, and Macklem, P T (1969). Frequency dependence of compliance as a test for obstruction in the small airways. Journal of Clinical Investigation, 48, 1097-1106.

Zapletal, A, Motoyama, E K, Van de Woestijne, K P, Hunt, V R, and Bouhuys, A (1969). Maximum expiratory flow-volume curves and airway conductance in children and adolescents. Journal of Applied Physiology, 26, 308-316.

Requests for reprints to: Dr L I Landau, Department of Thoracic Medicine, Royal Children's Hospital, Parkville, Victoria 3052, Australia. 